\title{
Men with prostate cancer and the accessibility to information - a literature review
}

\author{
Charlotte Dorisdatter Bjørnes ${ }^{1,2,3}$, Christian Nøhr ${ }^{2}$, Charlotte Delmar ${ }^{1}$, Birgitte Schantz Laursen ${ }^{1}$ \\ ${ }^{1}$ Department of Development and Planning, Aalborg University, Aalborg, DK; \\ ${ }^{2}$ Clinical Nursing Research Unit, Aalborg Hospital, Aarhus University Hospital, DK; \\ ${ }^{3}$ Department of Urology, Aalborg Hospital, Aarhus University Hospital, DK. \\ Email: bjoernes@plan.aau.dk
}

Received 4 July 2011; revised 19 August 2011; accepted 4 September 2011.

\begin{abstract}
Objective: To explore possible consequences of short stays in hospitals, as these short contacts reduce the patients' time for information and support. Method: A literature survey was carried out to get an insight in possible consequences by summarizing the state of knowledge on how men with prostate cancer undergoing prostatectomy surgery experience their contacts with the healthcare professionals. Results: A consequence is that often men with prostate cancer, treated with prostatectomy surgery, do not receive the individualized support, information, and dialogue they need, which leads to feelings of uncertainty, insecurity, and loss of control. The men use the Internet in their search for information and support, which makes them able to stay in control and be active, responsible partners in their own course of treatment. Conclusion: For men to feel secure and certain the accessibility of the healthcare professionals and the healthcare professionals' ability to individualize information and support are important aspects. Practice Implications: It is relevant to provide male cancer patients with tools that can underpin their contact to the healthcare professionals. Utilizing Web 2.0 technologies, Internet based tools can support exchange-ability, towards dialogue-based contacts, between men with prostate cancer and healthcare professionals.
\end{abstract}

Keywords: Health Communication; Access to Information; Short Stay Patients; Prostate cancer; Prostatectomy; Uncertainty; Active Patients; Health informatics; Online Social Support

\section{INTRODUCTION}

This paper documents the significance of patients' receiving individualized information through dialogue-based contacts with healthcare professionals. This is exemplified by summarizing the state of knowledge on how men with prostate cancer, undergoing prostatectomy surgery, experience their contacts with the healthcare professionals.

Secondary the paper points to the relevance in designing new health informatics tools that can support these dialogue-based contacts by utilizing Web 2.0 technologies. Web 2.0 websites differ from the static web pages established on Web 1.0 technologies where the users are limited to passive viewing. Web 2.0 technologies establish dynamic websites, as for example the users can interact and collaborate with each other in a dialogue.

\section{BACKGROUND}

Today's healthcare systems are characterised by short stays in hospital with planned discharge within one, two, or three days even after large operations. This decreases the time and opportunity for contact between the patients and the healthcare professionals. As contacts are situations or conditions where persons are able to exchange information, attitudes, feelings and so on [1], these short contacts reduce the patients' time for information and support.

Patient satisfaction surveys show that the patients are satisfied with short hospital stays [2-4]. However, qualitative studies have demonstrated that patients lack contact with healthcare professionals, and therefore often lack information and support [5-6]. This contradiction is explored in depth by focusing on the defined group of patients: Men with prostate cancer treated with prostatectomy surgery.

The number of men diagnosed with prostate cancer has increased with over 51 percent from 2000 to 2009. In 2009 prostate cancer ranked as the most frequent cancer among men [7]. A growing number of these men are treated with surgery; radical prostatectomy. Previously, these men were hospitalized up to 19 - 20 days in relation to the surgery [8]. Currently the stays in hospital, in relation to the surgery, are less than five days, which still 
decreases to planned discharge the day after surgery.

\section{METHOD}

Systematic review is selected as the data-gathering method for the study.

\subsection{Aim}

The aim of this literature survey is to summarize the state of knowledge on how men with prostate cancer experience their contacts with the healthcare professionals and what these men need and do to feel secure and certain. The specific research questions were:

1) How do men with prostate cancer, treated with prostatectomy surgery, experience their contacts with the healthcare professionals in clinical practice based on short stays?

2) What do patients need to feel secure and certain?

3) What is the role of the Internet?

\subsection{Literature Search}

The PubMed and CINAHL databases were searched. The inclusion criteria were English-language research articles. The study population was men with prostate cancer treated with prostatectomy surgery. When articles were of particular relevance related articles were explored by lower the demand in relation to the population. Therefore some articles relate to studies on men with prostate cancer in general, though still including men with prostate cancer treated with prostatectomy surgery. The exclusion criteria were publication age older than
1997, due to the focus on short stays in hospital, in today's healthcare system.

The PICO schema (Figure 1) reports the search history. The first and second research questions generated the search terms in the primary part of the literature search (primary search). Early findings [9-14] indicated that the Internet played a significant role, as this media was often mentioned in relation to information and support. To understand the role of the Internet the first two research questions were followed by the third research question: What is the role of the Internet? The third research question generated the secondary part of the literature search (secondary search). The Figure $\mathbf{1}$ also includes the exclusions of articles, when reading the abstracts: Due to the frequency of side effects as incontinence and sexual dysfunction after prostatectomy, these topics are wide-ranging in the literature. Articles, with these terms as major concept, were excluded if the abstracts did not include content of data related to the topics in current study. Reading abstracts from the secondary search excluded: Duplicates from the primary search, however, still including repeaters in relation to authors or findings generated in different areas of the same project. Excluded were also articles focusing on health informatics as decision support systems, as the population in current study already were in a course of treatment. Articles related to intervention studies were excluded, as these represented health informatics systems that the patients were invited or asked to use.

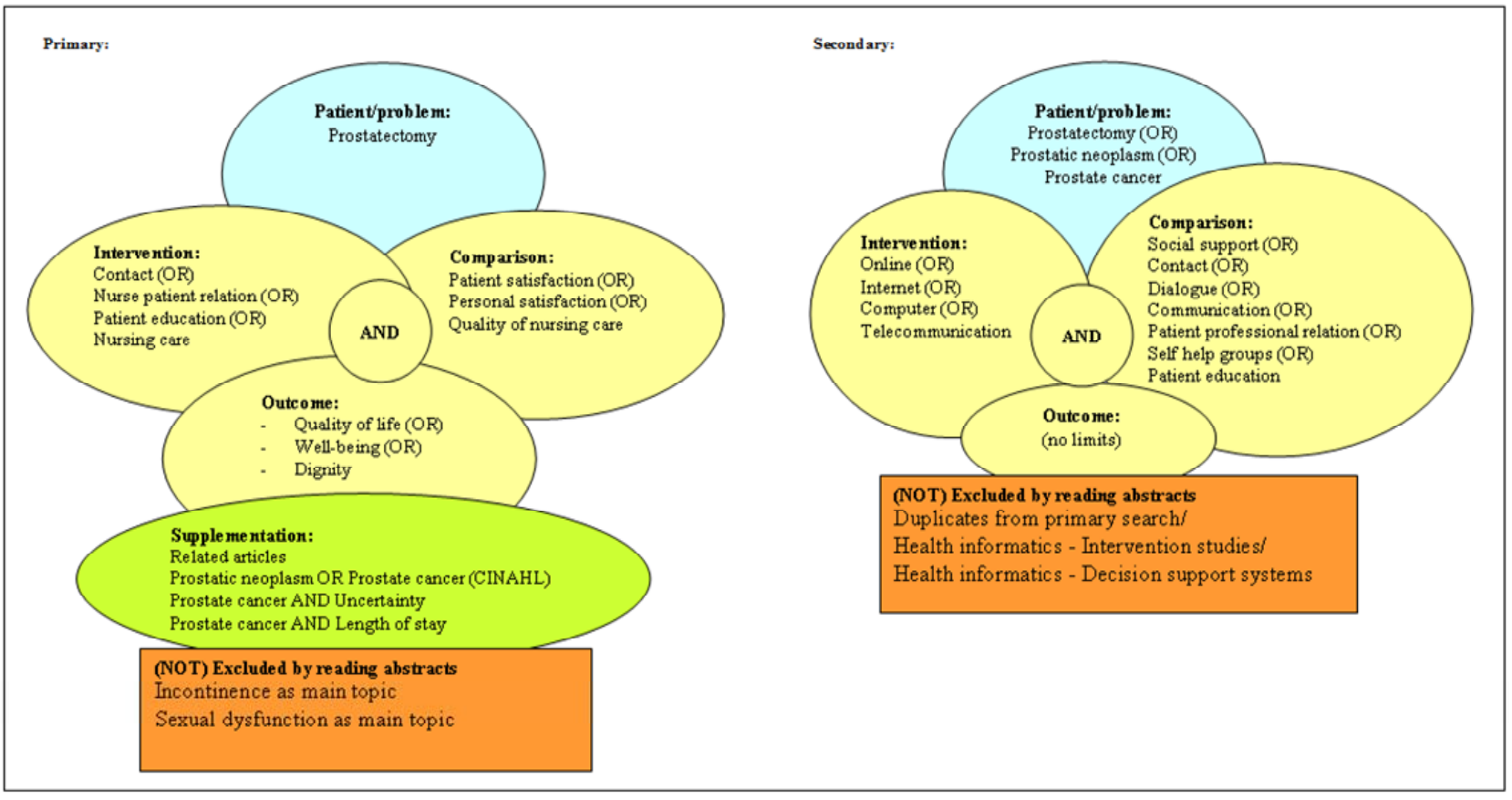

Figure 1. PICO schemas report the search terms. 
Searching PubMed and CINAHL February 2011 ac cording to the search terms in the primary search, the results were 78 in PubMed and three in CINAHL (Figure 2). Due to the small number in the CINAHL databases, the area was search through, as illustrated in the Supplementation. These supplementing searches expanded the number in the CINAHL to 56 including duplicates. Then the abstracts were read through. The numbers of relevant and research-based articles in the two databases were 29: 16 articles has specific focus on men with prostate cancer treated with prostatectomy surgery, whereas 13 articles also include other groups of men with prostate cancer. When categorizing the 29 articles according to the methods: 13 articles document survey studies and one article combines survey and interview. The rest; 15 articles report use of various forms of interview studies.

In the secondary search the focus was still on the same group of patients though expanded to men with prostate cancer in general. PubMed identified 141 titles. Searching CINAHL identified 56 titles whereas some were duplicates. The abstracts were read, leaving 18 researchbased articles, which contribute to understanding the role of the Internet in relation to the specified focus on information and communication according to the research questions. Six papers document findings from text analysis based on diverse philosophies. These studies analyse text that were generated on websites, which host different forms of online social support. Seven papers report survey studies and five describe findings generated by interview studies. Findings generated from a total of 47 articles are provided in relation to each of the three research questions.

\section{RESULTS}

\subsection{How Do the Men with Prostate Cancer Experience Their Contact with the Healthcare Professionals?}

The patient satisfaction surveys document that the men with prostate cancer in general are satisfied with short hospital stays in relation to their surgery $[8,15,16]$. However, interview based studies contributes to a diverse picture to that [9,10,12-14,17-29]. Milne et al. describe how the men had mixed perceptions about the benefit of short stays. This is underpinned by patients who explain how they were grateful that they had been allowed to stay in the hospital for two or three additional days. Sinfield et al. [28] conclude that although there were no widespread dissatisfaction, patients reportedproblems throughout their course of care. One of the problems was that information needs were often not identified or met. The lack in information is documented in several studies [12,18,20,23,24,27]. Phillips et al. [24] emphasize how the patients felt that they could have been better prepared by the healthcare professionals, even in cases in which no complications occurred. Moore and Estey [23] writes that the information deficits affected the patients' quality of life and healthy postoperative rehabilitation.

The short contacts reduce the patients' time for information and support. Though, it does not seem to be the amount of time, more likely how to get in contact and the quality of these contacts. In other words, contacts presuppose both accessibility and exchange-ability. As depicted in the following, accessibility means availability; it must be easy for the patients to get in contact with the healthcare professionals. And exchange-ability means; the ability to exchange information, as an essential basis for individualizing information.

Harden et al. [20] explain how the perception that all the healthcare professionals are extremely busy, for example at the hospital, deters many patients from asking the healthcare professionals, because they feel uncomfortable and self-conscious doing it. Hedestig et al. [21] describe how men with prostate cancer, btween their check-ups, often had difficulties containg the health care professionals or getting answers out of them, even though the men had questions they wanted to ask. This

\begin{tabular}{|l|l|l|l|l|l|}
\hline 1997-2011 & \multicolumn{3}{|c|}{ Results } & & \multicolumn{2}{c|}{ Results } \\
\hline Primary search & PubMed & CINAHL & Secondary search & PubMed & CINAHL \\
\hline Patient/problem & 14818 & 1033 & Patient/problem & 68256 & 8408 \\
\hline $\begin{array}{l}\text { Intervention } \\
\begin{array}{l}\text { Comparison } \\
\text { Outcome }\end{array}\end{array}$ & 78 & 3 & $\begin{array}{l}\text { Intervention } \\
\text { Comparison } \\
\text { Outcome }\end{array}$ & 141 & 56 \\
\hline $\begin{array}{l}\text { Supplementation } \\
\text { Reading Abstracts } \\
\text { Not (excluding) }\end{array}$ & - & 56 & $\begin{array}{l}\text { Reading Abstracts } \\
\text { Not (excluding) }\end{array}$ & & 18 \\
\hline \multicolumn{7}{|c|}{29} & Total number of articles: 47 \\
\hline
\end{tabular}

Figure 2. Number of research articles. 
illustrates why healthcare professionals must be easily accessible during the patients' course of treatment and care. The importance of accessibility is further describe by Harden et al. [20]. In their study, the men explain, how they function well most of the time, however, there were still ten percent of the time that was difficult. The men describe how their difficult issues easily became serious concerns and got out of proportion, when no one was listening to them. The men state that it would have been beneficial for them to have the opportunity to voice their concerns by having a person to call and ask a specific question [20]. The study by Milne et al. [13] illustrates how the accessibility is important. Milne et al. conclude that being home without readily and available support and advice from healthcare professionals caused anxiety and uncertainty. This is further underpinned by their own study, providing that the participants in the study experienced the researcher as an invaluable resource. The researcher collected the data by telephone and E-mails both pre and postoperative. The study itself became an information and support-intervention, which the participants benefit from, as it helped them to talk to the researcher and have the opening to telephone or Email the researcher [13]. It is essential that the patients experience the healthcare professionals as easily accessible both at the hospital and when the patients are home.

The importance of the exchange-ability is for example shown in the study by Iyigun et al. [27], as the men explained how the information should be individualized: The healthcare professionals must keep the patients' cultural level and psychological state in mind when providing the information. Harden et al. [20] describe how the participants in their study told that the need for information was great, but they all needed different information or needed it in a different way than others. The men wanted someone to listen to their specific needs and fears and to help them find answers or just review information. When a healthcare professional aimed to individualize the information the men felt supported [20]. Again, it does not seem to be the amount of time, more likely the quality of the information and support, meaning the healthcare professionals ability to exchange experiences, and so on, to generate individualized information upon that. The men need the healthcare professionals to build the information and support on their individual questions, experiences, and resources. The men require a contact where the healthcare professionals enter into a dialogue with them, as the dialogues are prerequisite in individualising the information and support. A survey study by Smith et al. [30] document how a little more than half of the men express some levels of unmet psychological needs. Uncertainty about the future was for example an important area of unmet need. The dialogues are prerequisite if the healthcare professionals shall be able to discover such uncertainty and meet the needs of the particular patient. Thus, the healthcare professionals' accessibility and ability to individualize information and support, based on exchange-ability, are important aspects for men with prostate cancer treated with prostatectomy surgery.

In summary, this section illustrates that even though the short contacts reduce the patients' time for information and support it does not seem to be the amount of time that is most important. Instead it is how to get in contact with the healthcare professionals and the quality of the contacts, meaning the contacts need to be dialogue-based.

\subsection{What Do Patients Need to Feel Secure and Certain?}

The consequences, when men with prostate cancer lack dialogue with, and therefore information and support from, healthcare professionals, are explored by searching across the papers $[9,12-14,20,21,23,24,27,28]$. The findings are illustrated in Figure 3. As depicted, lacking information can start a negative process in which feelings of uncertainty and insecurity can affect the men's ability to cope. When lacking information there is a risk that the men experience disempowerment, which is feelings of powerlessness or helplessness that reduces the amount of control that someone, has over a situation [1]. In contradiction, obtaining contact, enter dialogues, and receiving individualized information and support are related to experiences and feelings, which support the positive process (Figure 3). Empowerment is the process of giving somebody power in a particular situation; to give someone more control over their own life or the situation they are in [1].

In the paper by Iyigun et al. [27] the negative process is illustrated, as lack of knowledge causes insecurity. The study documents how the men felt anxious going home because they were afraid of complications. It is emphasized how the anxiety about going home is due to lack of adequate information from the healthcare professionals. This is underpinned by the few men, who obtained information from the healthcare professionals, as they were more comfortable afterwards [27]. Sinfield et al. [28] explain that information interventions improve the patients' knowledge and understanding. Individualized, clearly information and communication influence the patients' ability to make decisions and participate. Butler et al. [10] identify how male cancer patients' coping was influenced by receiving individualized information. Thus Maliski et al. [12] conclude that healthcare professionals can hasten thepatients' ability to regain a sense of mastery by providing information and being available. 

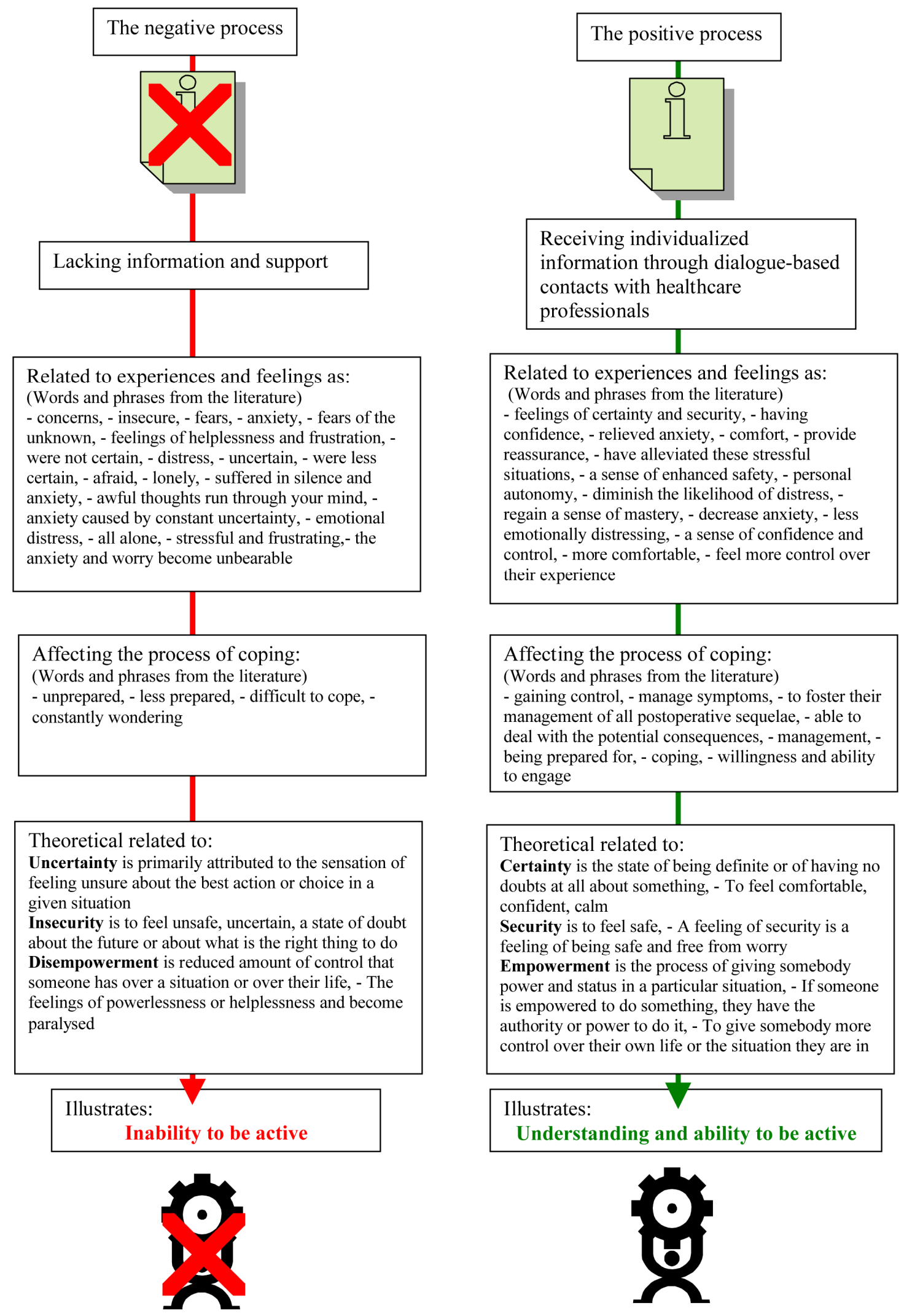

Figure 3. The negative and positive process of coping. 
The healthcare professionals' accessibility and ability to individualize information and support are important aspects for men with prostate cancer treated with prostatectomy surgery, to feel secure and certain. By providing information and support healthcare professionals supports the patients' process of coping.

In summary, this section gives a picture of the importance of receiving information and support in a course of treatment and care. By providing information and support healthcare professionals may be able to empower the patients. The empowered patient is also the active patient.

\subsection{What Is the Role of the Internet?}

The findings illustrate how men with prostate cancer use the Internet to cope with the lacking information and support. They use the online media to get information about the diagnosis prostate cancer, treatment options, and other topics related to a course of treatment [31-40]. Another purpose is to achieve social support; online social support [41-46]. Huber et al. [42] describe online social support as social interactions and Dickerson et al. [32] explain it as online friendship.

The study by Dickerson et al. [32] illustrate how the important elements of social support exist in the Internet based groups. In the online social support groups, the patients share their stories, which contribute to recognition and reflections, which again generate other perspectives and new knowledge. A patient, in their study, tells how using the Internet and recognising other people with identical problems were reassuring and helped him much. Another patient showed how sharing experiences with other patients generated insight and developed selfmanagement skills. Huber et al. [42] emphasize that the Internet based social interactions can be important for the individual in coping with and during his own course of treatment.

In general Iyigun et al. [27] explain how some men learn to cope themselves, when they are not receiving information or when facing problems, and therefore for example use the Internet. Van de Poll-Franse et al. [38] describe how patients by themselves searched for information on the Internet about the cancer, treatment, and the consequences of treatment in general. Their study illustrates how the patients use the Internet in every step of their course of treatment, though varying in relation to topics and amount of time. Most of the patients, who used the Internet to find information, felt themselves better informed. Buntrock et al. [40] characterize the Internet users as information seekers and point to how these patients become active participants in their course of treatment and care. Milne et al. [13] explain how men with prostate cancer use the Internet to be in front. The men experience a sense of confidence and control for example by consulting a variety of websites on the Internet prior to meetings with the healthcare professionals. Broom [47] explains how the Internet allows the patients to "do something". The patients experience themselves as competent and feel as they do not only rely on the doctor. The patients become capable to take part in decisionmaking, which also increase their sense of control over their treatment process. As such the Internet usage reduces the patients' uncertainties and supports the patients' involvement in making decision along their course of treatment [47]. Dickerson et al. [32] found that the patients themselves felt more comfortable and knowledgeable by utilizing the Internet as a tool during their course of treatment. The Internet is a tool that generated understandings, for example about one's own situation. Dickerson et al. describe that men with cancer incorporate Internet use into their cancer journey and become problem solvers. The men use the Internet to enhance their sense of control. The men seek to be proactive, prepared, and responsible, and thereby trying to change the provider-patient relationships towards collaboration and open communication. The men use the Internet information for verification and to clarify, compare, and validate the information obtained during their course of treatment and care. Dickerson et al. [32] point to how the men became experts at finding resources online to confirm their decisions, realizing the need to make choices, and to monitor their progress or possible reoccurrence.

The men use the Internet to stay in control and engage in their own course of treatment as active and responsible partners.

\section{DISCUSSION}

The aim of this literature survey was to summarize the state of knowledge on how men with prostate cancer, treated with prostatectomy surgery, experience their contact with the healthcare professionals. A relative small number of studies were found. None had a defined focus on these men and their experience of contacts with healthcare professionals. However, this article reviews the literature for men's experience on themes relevant in the contact between men and healthcare professionals: Information; support; and dialogues.

The literature survey identified that the patients often do not receive the individualized support, information, and dialogue that they need. As a result of the lack of contact, the men struggle with feelings of insecurity and uncertainty, often followed by loss of control.

Even so the men had mixed feelings about the short stays at hospital. The contradiction based on different research methods, as illustrated in the introduction, is comparable with these findings. Though the interview 
based studies that were reviewed specify the difficulties. This elaboration gives an understanding of the complexity of and correlations in human meaning. The short stays in hospital limits and defines the time for contact between the patients and the healthcare professionals, as the contacts are both dated and categorized. However the patients' need for contact cannot be defined in the same matter.

The accessibility of the healthcare professionals and the healthcare professionals' ability to individualize information and support are important aspects for men with prostate cancer treated with prostatectomy surgery. The opportunity for male patients to get in contact with healthcare professionals, and the quality of these contacts, is related to male patients' chance to feel secure and to stay in control. The men require a contact where the healthcare professionals enter into a dialogue with them, as the dialogues are prerequisite for individualising the information and support.

A literature survey by Shaha et al. [48] document that people with cancer in general often experience uncertainty due to lack of information. Shaha et al. [48] illustrate how uncertainty is present in different, and often in all, phases of a cancer trajectory, although with varying intensity and based on diverse issues. Shaha et al. emphasize the importance of information, support, and individual approaches to care to minimize the negative aspects of uncertainty, especially in the light of the increasing ambulatory approaches to cancer care in general.

A general conclusion, in the literature, is that there is still a need to develop new ways and tools to provide the patients with information and support. Based on an intervention study using survey evaluation Berglund et al. [49] support this significant conclusion and describes that this is a crucial task for the healthcare sector. Healthcare professionals seem to recognize the importance of providing individual information and support, but need to determine the best manner in which to provide it and foremost important to incorporate it into practice [12, 18,20,23]. Sharpley et al. [50] stress that the ideal format for patient information still needs to be identified, which require further research. For instance how to include the provision of information, assist with navigating through large amounts of information, dispelling misinformmation, encouraging acquisition of self-care skills, and providing individual information and support to decrease insecurity.

Especially, when having men as patients it can be relevant to develop new health informatics tools. The findings illustrate that men with prostate cancer use the Internet to get information and support. The men use the Internet to stay in control and engage in their own course of treatment as active and responsible partners. Though every single patient is an individual, there are indications of differences men versus women as patients. Dickerson et al. [32] describe how men focus on problem solving, determine effects, treatments, and symptom management in a functional way. Male cancer patients actively organize information, monitor for reoccurrence, prepare, facilitate, and validate ahead of their contacts with healthcare professionals. Previous studies, with focus particularly on men as patients, state that male patients want to in stay control and remain autonomy. Men like to act. Therefore information, advice, and tools that support actions, are important in their course of treatment [50-57]. Hence, it is relevant to provide male cancer patients with tools that can underpin their contact to and dialogues with the healthcare professionals.

The short stays in hospital limits and defines the time for contact between the patients and the healthcare professionals, as the contacts are both dated and categorized. However the patients' need for contact cannot be defined in the same matter. The men require a contact where the healthcare professionals enter into a dialogue with them, as the dialogues are prerequisite for individualising the information and support. The relatively new Internet technologies Web 2.0 establish dynamic websites, which allow the users to do more than just retrieve information, as on Web 1.0 sites [1]. Thereby Web 2.0 websites differ from the static web pages established on Web 1.0 technologies where the users are limited to passive viewing. A Web 2.0 website allows users to interact and collaborate with each other in a dialogue. Users can provide and control the data on a Web 2.0 site. The contents are user-generated and the users are interactive and able to communicate with each other. The asynchronous environments, which the Web 2.0 technologies provide, are a significant way to expand the time for contacts besides the restricted formal face-to-face contacts at hospital. Utilizing this expansion in flexible time healthcare professionals have the opportunity to comply with the contradiction between the patients' needs for contact and the intensifying of patients' short stays at hospital. The course of care can go beyond the formal face-to-face contacts between the patients and the healthcare professionals, so that the patients have the opportunity to feel informed and supported, and thereby empowered, even at home. As such the online asynchronous health informatics tools can be one of the components to accommodate these organisational changes.

In general, it is suggested that healthcare professionals do have a responsibility in creating Internet based reliable information and online social support groups for the patients. This is consistent with the findings, when focusing on men with prostate cancer. Broom [47] explains how the empowering of the patients changed the roles between the patients and the healthcare profession- 
als, as the Internet allows the patients to act. The patients' activities are grounded on the information on the Internet, whether it is reliable or not. As illustrated Dickerson et al. [32] describe that the men use the online information to validate the information from the healthcare professionals. However, the patients are also aware of the importance of checking the quality of the information available on the Internet. Therefore most of the men consider the information cautiously. Van de Poll-Franse et al. [38] emphasize the importance of healthcare professionals taking active part in the future use and development of Internet based tools. Pautler et al. [34] specify the importance in healthcare professionals participating in the development of information websites, as these may influence the patients' decisions regarding treatment. Hence, the healthcare professionals may acknowledge the role of Internet in their contact with each patient. Furthermore, the healthcare professionals may use their organisations websites to provide comprehensive and reliable information.

Healthcare professionals' active involvement in developing Internet based tools is consistent with the patients' request, as Van de Poll-Franse et al. [38] document. The patients prefer to get reliable information from websites made, or recommend, by their healthcare professionals, for example the oncologist and the hospital. Hence, using the Internet actively, the healthcare professionals would have a tool to underpin their contact with the patients.

Many patients describe their wishes about future use of the Internet, for example access to medical files and test results [38]. Two survey based studies report men's interest in [58] and satisfaction with [59] access to their own medical record. Cathala et al. supplemented the medical files by inviting the patients to fill out quality of life questionnaires to document treatment outcome. A contact page allows the patient and physician to exchange information by text. In both studies [58,59] the men appraised the access to the Internet medical record positively and the researchers emphasize the relevance in further developing. Based on the surveys it is indicated that the contact to the doctor becomes closer and the patients are more capable to engage in shared medical decision making with their doctor. However, the questionnaire-based findings did not reveal whether the access to medical records or the exchanging of information actually seemed to be more individualized or managed to meet the patients' individual needs in support, information, and dialogue $[58,59]$. Therefore, it seems relevant that both healthcare professionals and patients not only are involved when evaluating new health informatics tools, but also are engaged in future design and development of health informatics systems.

\section{Limitations}

The defined population and research questions generated a relative limited number of articles. Furthermore, several papers were excluded, because their focus was mainly incontinence. Some of these papers could have been relevant in relation to the concrete population. However the overall focuses were contacts, dialogues, information, and support, in the light of short stay surgery, and not long term complications after surgery.

The area of health informatics tools expands quickly. This can for example be illustrated by the increasing number of decision support systems to men with prostate cancer. According to the exclusion criteria, studies related to that topic were not a part of the current study. These articles could have contributed to the third research question: What is the role of the Internet? However the answer to the third research question shall be seen in relation to the first and second research questions.

The research questions are generated from a problem experienced in nursing care. Looking at the search terms it is clear that the study is born in nursing. Expanding the search terms to other professions for example doctors and to the health informatics field would potentially give various perspectives. Though, the patients needs, will be identical.

\section{CONCLUSIONS}

The literature survey identify that men with prostate cancer treated with prostatectomy surgery often do not receive the individualized support, information, and dialogue they need. Because of that the men struggle with feelings of uncertainty, insecurity, and loss of control. However, contacts based on short stays at the hospital seem to be acceptable for men with prostate cancer, treated with prostatectomy surgery. The importance, in relation to the patients' contact with healthcare professionals, is not the length and amount of time. Instead accessibility and exchange-ability are significant aspects. For men to feel secure and certain, the healthcare professionals must be easy to get in contact with during the whole course of treatment and care. Concurrently, the healthcare professionals' ability to exchange information, and thereby to individualize information and support based on dialogues with the particularly man, is essential. Providing information and support healthcare professionals may be able to empower the patients, and the empowered patient is also the active patient.

The findings demonstrate that men with prostate cancer use the Internet in their search for information and support. The Internet helps the men to stay in control and to engage in their own course of treatment as active and responsible partners.

\section{PRACICE IMPLICATIONS}

The results may be a starting point for the development 
of new health informatics tools by combining Web 1.0 technologies with Web 2.0 technologies. Seeing that it is relevant to provide male cancer patients with tools that can underpin their contacts to and dialogues with the healthcare professionals and in combination, the Internet is already a common used media. It seems relevant that both healthcare professionals and patients are engaged in future development of health informatics systems, as a collaborative development and use of Internet based tools could underpin the exchange-ability, towards dialoguebased contacts between men with prostate cancer and healthcare professionals.

\section{ACKNOWLEDGEMENTS}

The authors wish to acknowledge funding from: The Novo Nordisk Foundation, DOF Det Obelske Familiefond, Danish Nursing Research Society, Harboefonden. The funding source had no involvement in the study. There is no conflict of interest for the authors associated with this study. The manuscript is revised by: Lene Sømod Flou, BA in English Languages, Staff Member with University Degree, Aalborg University.

\section{REFERENCES}

[1] Ordbogen.com. Ordbogen.com. Danmarks største online ordbog (The large online dictionary in Denmark). (2011) Retrieved from http://www.ordbogen.com/. Ref Type: Computer Program

[2] Marx, C.I., Rasmussen, T., Jakobsen, D.H., Ottosen, C., Lundvall, .L. and Ottesen, B.S. et al. (2006) Accelerated course after operation for ovarian cancer. Ugeskrift for Leger, 168, 1533-1536.

[3] Husted, H., Hansen, H.C., Holm, G., Bach-Dal, C., Rud, K. and Andersen, L.K. et al. (2006) Accelerated versus conventional hospital stay in total hip and knee arth- roplasty III: patient satisfaction. Ugeskrift for Leger, 168, 2148-2151.

[4] Kehlet, H. (2001) Accelererede operationsforløb. (Accelerated surgical stay programs - a professional and administrative challenge). Ugeskrift for Leeger, 163, 420-424.

[5] Wagner, L., Carlslund, A.M., Moller, C. and Ottesen, B. (2004) Patient and staff (doctors and nurses) experiences of abdominal hysterectomy in accelerated recovery programme. A qualitative study. Danish Medical Bulletin, 51, 418-421.

[6] Norlyk, A. (2008) The experience of fast track postoperative rehabilitation regimen: The patients' perspective. Kli- nisk Sygepleje, 22, 53-63.

[7] Cancerregisteret, (2009) Cancer Register 2009. Sundhedsstyrelsen, National Board of Health.

[8] Litwin, M.S., Shpall, A.I. and Dorey, F. (1997) Patient satisfaction with short stays for radical prostatectomy. Urology,49, 898-905. doi:org/10.1016/S0090-4295(97)00103-9

[9] Burt, J., Caelli, K., Moore, K. and Anderson, M. (2005) Radical prostatectomy: men's experiences and postoperative needs. Journal of Clinical Nursing, 14, 883-890. doi:org/10.1111/j.1365-2702.2005.01123.x

[10] Butler, L., Downe-Wamboldt, B., Marsh, S., Bell, D. and
Jarvi, K. (2001) Quality of life post radical prostatectomy: a male perspective. Urology Nursing, 21, 283-288.

[11] Coreil, J. and Behal, R. (1999) Man to Man prostate cancer support groups. Cancer Practice, 7, 122-129. doi:org/10.1046/j.1523-5394.1999.07307.x

[12] Maliski, S.L., Heilemann, M.V. and McCorkle, R. (2001) Mastery of postprostatectomy incontinence and impotence: his work, her work, our work. Oncology Nursing Forum, 28, 985-992.

[13] Milne, J.L., Spiers, J.A. and Moore, K.N. (2007) Men’s experiences following laparoscopic radical prostatectomy: A qualitative descriptive study. International Journal of Nursing Studies, 45, 765-774.

[14] Powel, L.L. and Clark, J.A. (2005) The value of the marginalia as an adjunct to structured questionnaires: experiences of men after prostate cancer surgery. Quality of life research: An International Journal of quality of life aspects of treatment, care and rehabilitation, 14, 827- 835.

[15] Kirsh EJ, Worwag EM, Sinner M, Chodak GW (2000) Using outcome data and patient satisfaction surveys to develop policies regarding minimum length of hospitalization after radical prostatectomy. Urology, 56, 101-106. doi:org/10.1016/S0090-4295(00)00594-X

[16] Klein, E.A., Grass, J.A., Calabrese, D.A., Kay, R.A, Sargeant, W. and O'Hara, J.F. (1996) Maintaining quality of care and patient satisfaction with radical prostatectomy in the era of cost containment. Urology, 48, 269-276. doi:org/10.1016/S0090-4295(96)00160-4

[17] Jakobsson, L. (2002) Indwelling catheter treatment and health-related quality of life in men with prostate cancer in comparison with men with benign prostatic hyperplasia. Scandinavian Journal of Caring Sciences, 16, 264-271. doi:org/10.1046/j.1471-6712.2002.00096.x

[18] Davison, B.J., Moore, K.N., MacMillan, H., Bisaillon, A., Wiens, K. (2004) Patient evaluation of a discharge program following a radical prostatectomy. Urology Nursing, 24, 483- 489.

[19] Gray, R.E., Fitch, M.I., Phillips, C., Labrecque, M., Klotz, L. (1999) Presurgery experiences of prostate cancer patients and their spouses. Cancer Practice, 7, 130-135. doi:org/10.1046/j.1523-5394.1999.07308.x

[20] Harden, J., Schafenacker, A., Northouse, L., Mood, D., Smith, D. and Pienta, K. et al. (2002) Couples' experiences with prostate cancer: focus group research. Oncology Nursing Forum, 29, 701-709. doi:org/10.1188/02.ONF.701-709

[21] Hedestig, O., Sandman, P.O., Tomic, R. and Widmark, A. (2005) Living after radical prostatectomy for localized prostate cancer: a qualitative analysis of patient narratives. Acta Oncologica, 44, 679-686. doi:org/10.1080/02841860500326000

[22] Jakobsson, L., Hallberg, I.R. and Loven, L. (1997) Met and unmet nursing care needs in men with prostate cancer. An explorative study. Part II. European Journal of Cancer Care, 6, 117-123. doi:org/10.1046/j.1365-2354.1997.00020.x

[23] Moore, K.N. and Estey, A. (1999) The early post-operative concerns of men after radical prostatectomy. Journal of Advanced Nursing, 29, 1121-1129. doi:org/10.1046/j.1365-2648.1999.00995.x

[24] Phillips, C., Gray, R.E., Fitch, M.I., Labrecque, M., Fergus, K. and Klotz, L. (2000) Early postsurgery experience of prostate cancer patients and spouses. Cancer Practice, 8, 165-171. doi:org/10.1046/j.1523-5394.2000.84009.x 
[25] Rondorf-Klym, L.M. and Colling, J. (2003) Quality of life after radical prostatectomy. Oncology Nursing Forum, 30, E24-E32. doi:org/10.1188/03.ONF.E24-E32

[26] Boberg, E.W., Gustafson, D.H., Hawkins, R.P., Offord, K.P., Koch, C., Wen, K.Y. et al. (2003) Assessing the unmet information, support and care delivery needs of men with prostate cancer. Patient Education and Counselling, 49, 233-242. doi:org/10.1016/S0738-3991(02)00183-0

[27] Iyigun, E., Ayhan, H. and Tastan, S. (2009) Perceptions and experiences after radical prostatectomy in Turkish men: A descriptive qualitative study. Applied Nursing Research, 24, 101-109. doi:org/10.1016/j.apnr.2009.04.002

[28] Sinfield, P., Baker, R., Agarwal, S. and Tarrant, C. (2008) Patient-centred care: What are the experiences of prostate cancer patients and their partners? Patient Education and Counselling, 73, 91-96. doi:org/10.1016/j.pec.2008.05.001

[29] Hedestig, O. (2006) Att leva med lokaliserad prostatacancer. “Oss män emellan". (Living with localised prostate cancer. between men). Department of Radiation Sciences, Oncology, and Department of Nursing, Medical Faculty, Umeaa University, Sweden.

[30] Smith, D.P., Supramaniam, R., King, M.T., Ward, J., Berry, M. and Armstrong, B.K. (2007) Age, health, and education determine supportive care needs of men youn- ger than 70 years with prostate cancer. Journal of Clinical Oncology: Official Journal of the American Society of Clinical Oncology, 25, 2560-2566.

[31] Davison, B.J., Keyes, M., Elliott, S., Berkowitz, J. and Goldenberg, S.L. (2004) Preferences for sexual information resources in patients treated for early-stage prostate cancer with either radical prostatectomy or brachytherapy. British Association of Urological Surgeons, 93, 965969.

[32] Dickerson, S.S., Reinhart, A., Boemhke, M. and Akhu- Zaheya, L. (2010) Cancer as a problem to be solved: internet use and provider communication by men with cancer. Computers, Informatics, Nursing: CIN, Epub ahead of print Oct 21.

[33] Nagler, R.H., Romantan, A., Kelly, B.J., Stevens, R.S. and Gray, S.W., et al. (2010) How Do Cancer Patients Navigate the Public Information Environment? Understanding Patterns and Motivations for Movement Among Information Sources. Journal of Cancer Education: The Official Journal of the American Association for Cancer Education, 360-370.

[34] Pautler, S.E., Tan, J.K., Dugas, G.R., Pus, N., Ferri, M. and Hardie, W.R. et al. (2001) Use of the internet for selfeducation by patients with prostate cancer. Urology, 57, 230-233. doi:org/10.1016/S0090-4295(00)01012-8

[35] Pinnock, C.B. and Jones, C. (2003) Meeting the information needs of Australian men with prostate cancer by way of the internet. Urology, 61, 1198-1203. doi:org/10.1016/S0090-4295(03)00016-5

[36] Ramsey, S.D., Zeliadt, S.B., Neeraj, K.A. and Arnold, L.P., et al. (2009) Access to information sources and treatment considerations among men with local stage prostate cancer. Urology, 74, 509-515.

[37] Rozmovits, L. and Ziebland, S. (2004) What do patients with prostate or breast cancer want from an Internet site? A qualitative study of information needs. Patient Education and Counselling, 53, 57-64. doi:org/10.1016/S0738-3991(03)00116-2
[38] Poll-Franse, L.V.V.D. and Eenbergen, V.M.C.H.J. (2008) Internet use by cancer survivors: current use and future wishes. Support Care Cancer, 16, 1189-1195. doi:org/10.1007/s00520-008-0419-z

[39] Ziebland, S. (2004) The importance of being expert: the quest for cancer information on the Internet. Social Science \& Medicine, 59, 1783-1793. doi:org/10.1016/j.socscimed.2004.02.019

[40] Buntrock, S., Hopfgarten, T., Adolfsson, J., Onelo, E. and Steineck, G. (2007) The Internet and prostate cancer patients. Searching for and finding information. Scandi- navian Journal of Urology and Nephrology, 41, 367-374. doi:org/10.1080/00365590701303827

[41] Gooden, R.J. and Winefield, H.R. (2007) Breast and prostate cancer online discussion boards: a thematic ana- lysis of gender differences and similarities. Journal of Health Psychology, 12, 103-114. doi:org/10.1177/1359105307071744

[42] Huber, J., Ihrig, A. and Peters, T., et al. (2010) Decisionmaking in localized prostate cancer: lessons learned from an online support group. BJU International, Epub ahead of print.

[43] Klemm, P., Hurst, M., Dearholt, S.L. and Trone, S.R. (1999) Gender differences on Internet cancer support groups. Computers in Nursing, 17, 65-72.

[44] Owen, J.E., Klapow, J.C., Roth, D.L. and Tucker, D.C. (2004) Use of the internet for information and support: disclosure among persons with breast and prostate cancer. Journal of Behavioural Medicine, 27, 491-505. doi:org/10.1023/B:JOBM.0000047612.81370.f7

[45] Seale, C., Ziebland, S. and Charteris-Black, J. (2006) Gender, cancer experience and internet use: a comparative keyword analysis of interviews and online cancer support groups. Social Science \& Medicine, 62, 2577-2590. doi:org/10.1016/j.socscimed.2005.11.016

[46] Sullivan, C.F. (2003) Gendered cybersupport: a thematic analysis of two online cancer support groups. Journal of Health Psychology, 8, 83-103.

doi:org/10.1177/1359105303008001446

[47] Broom, A. (2005) The impact of internet use on disease experience and the doctor-patient relationship. Qualitative Health Research, 15, 325-345. doi:org/10.1177/1049732304272916

[48] Shaha, M., Cox, C.L., Talman, K. and Kelly, D. (2008) Uncertainty in breast, prostate, and colorectal cancer: implications for supportive care. Journal of Nursing Sch- olarship, 40, 60-67. doi:org/10.1111/j.1547-5069.2007.00207.x

[49] Berglund, G., Petersson, L.M., Eriksson, K.R. and Haggman, M. (2003) “Between men”: patient perceptions and priorities in a rehabilitation program for men with prostate cancer. Patient Education and Counselling, 49, 285292. doi:org/10.1016/S0738-3991(02)00186-6

[50] Sharpley, C.F. and Christie, D.R. (2007) Patient information preferences among breast and prostate cancer patients. Australasian Radiology, 51, 154-158

[51] Agger, N.P. and Ølgod, J. (2001) Mænd og kræft. Anbefalinger og handlingskatalog til alle der arbejder med mandlige kræftpatienter. Men and Cancer. Recom- mendations and Catalogue of Actions for Professionals Working with Male Cancerpatients, Kræftens Bekæmpelse, the Danish cancer society. 
[52] Agger, N.P. (2002) Mænd. (Men). Mennesker Med Kræft. (People with Cancer), Copenhagen, Munksgaard.

[53] Joergensen, S.E. (1999) Mænd med kræft-en interviewundersøgelse, Men with Cancer-A Interview Study, the Danish cancer society.

[54] Johnsen, A.T. (2006) Kræftpatientens verden-en undersøgelse af, hvilke problemer danske kræftpatienter oplever. Litteraturgennemgang og interviews. (The world of a cancer patient-a survey on problems experienced by Danish cancer patients. A Survey of the Literature and Interviews, bispebjerg hospital.

[55] Olsen, H., Gram, J. and Madsen, S.A. (2007) Uddannelse i kommunikation og dialog med mænd. Kompendium med fokus på mænds sundhed og sygdomme. (Instruction in communication and dialogue with men. A Compen- dium with Focus on Men in Health and Illness, Men's Health Week.

[56] Ølgod, J. (1999) Breve fra mænd med kræft. Letters from Men with Cancer, the Danish cancer society.

[57] Simonsen, S.S. (2006) Mænd, sundhed og sygdom-Ronkedorfænomenet. Men, Health and Illness.

[58] Pai, H.H. and Lau, F. (2005) Web-based electronic health information systems for prostate cancer patients. The Canadian Journal of Urology, 12, 2700-2709

[59] Cathala, N., Brillat, F., Mombet, A., Lobel, E., Prapotnich, D. and Alexandre, L. et al. (2003) Patient followup after radical prostatectomy by Internet medical file. The Journal of Urology, 170, 2284-2287.

doi:org/10.1097/01.ju.0000095876.39932.4a 